\title{
KOMUNIKASI HEALTH EDUCATION TERHADAP PENGETAHUAN LANSIA TENTANG PERTOLONGAN PERTAMA PADA DIAREDI WILAYAH KERJA PUSKESMAS NGADILUWIH KABUPATEN KEDIRI
}

\author{
Prima Dewi Kusumawati, Nafa Zunaidah Fahma, Dhita Kurnia Sari \\ Stikes Surya Mitra Husada \\ prima.lppmstrada@gmail.com
}

\begin{abstract}
The delay of the first aid on the elderly's diarrhea to prevent complications like dehydration was caused due to the lack of knowledge about its first aid. Communication of health education is a way to increase their knowledge. The purpose of this research is to know the influence of health education to the elderly's knowledge about first aid on diarrhea in working area of Ngadiluwih Health Center Kediri Regency. Research design used in this research was pre-experimental with one-group pra-post test. Population was all $\geq 60$ years old elderly who were active in elderly's health center and lived in Tales Village Working Area Health Center Ngadiluwih Kediri with 98 samples taken by simple random sampling. The instrument used pre-post test knowledge questionnaires about first aid on diarrhea and then analyzed by Wilcoxon Test. The results of elderly before having health education about first aid on diarrhea, there were 83 respondents (84.6\%) who were less knowledgeable, while after having health education 85 respondents (86.7\%) were either knowledgeable. Wilcoxon test with $p$ value $=0.000<0.05$ thenrefore $\mathrm{HO}$ is rejected, which means there was influence of health education on elderly's knowledge about first aid on diarrhea in working area of Ngadiluwih Health Center Kediri Regency. Health education and direct information can increase knowledge.
\end{abstract}

Keywords: Communication of health education, knowledge, First aid on diarrhea, Elderly

\begin{abstract}
Abstrak
Keterlambatan pertolongan pertama pada diare lansia untuk mencegah komplikasi seperti dehidrasi disebabkan karena kurangnya pengetahuan tentang diare serta pertolongan pertamanya. Komunikasi health education merupakan cara untuk meningkatkan pengetahuan melalui komunikasi dalam bentuk pendidikan. Tujuan penelitian ini untuk mengetahui pengaruh komunikasi health education terhadap pengetahuan lansia tentang pertolongan pertama pada diare di Wilayah Kerja Puskesmas Ngadiluwih Kabupaten Kediri. Desain penelitian pre-experimental dengan rancangan one-group pra-post test. Populasinya adalah semua lansia usia $\geq 60$ tahun yang aktif dalam posyandu lansia dan tinggal di Desa Tales Wilayah Kerja Puskesmas Ngadiluwih Kabupaten Kediri, sampel 98 responden secara simple random sampling. Instrumen yang digunakan adalah kuesioner pengetahuan pra-post test tentang pertolongan pertama pada diare kemudian dianalisis dengan Uji Wilcoxon. Hasil pengetahuan lansia sebelum diberikan health education tentang pertolongan pertama pada diare didapatkan 83 responden $(84,6 \%)$ berpengetahuan kurang, sesudah health education sebanyak 85 responden $(86,7 \%)$ berpengetahuan baik. Uji wilcoxon dengan $\mathrm{p}$ value $=0,000<$
\end{abstract}


0,05 maka H0 ditolak yang berarti ada pengaruh health education terhadap pengetahuan lansia tentang pertolongan pertama pada diare di Wilayah Kerja Puskesmas Ngadiluwih Kabupaten Kediri. Health education dan informasi yang diberikan secara langsung dapat meningkatkan pengetahuan.

Kata Kunci: Komunikasi Health Education, Lansia, Pengetahuan, Pertolongan Pertama pada Diare

\section{PENDAHULUAN}

Diare merupakan masalah kesehatan dunia terutama di negara-negara berkembang termasuk Indonesia. Penyakit diare atau gastroenteritis masih sering menimbulkan KLB (Kejadian Luar Biasa) dengan penderita banyak dalam waktu singkat. KLB menjadi salah satu penyebab utama kematian. Kematian sering terjadi pada pada anak-anak atau usia lanjut, di mana pada usia tersebut rentan terhadap dehidrasi. Kondisi tersebut disebabkan karena kurangnya pemahaman tentang penyakit diare sehingga keterlambatan pertolongan pertama yang dilakukan menyebabkan dehidrasi pada pasien diare semakin parah, bahkan mengakibatkan kematian (Tjay \& Rahardja, 2007).

Indonesia merupakan salah satu negara berkembang dengan angka kejadian diare yang masih tinggi. Berdasarkan karakteristik penduduk, kelompok umur balita adalah yang paling tinggi menderita diare, sementara lansia umur 55-65 tahun yaitu sebanyak $1,9 \%$ dan 3,2\% (Kemenkes RI., 2013).

Pada tahun 2014 jumlah penderita diare di Jawa Timur mencapai 5.630.000 kasus. Sedangkan data di Puskesmas seluruh Jawa Timur menunjukkan diare termasuk dalam 3 penyakit terbanyak. Berdasarkan data yang diperoleh dari Puskesmas Ngadiluwih Kabupaten Kediri, pada tahun 2014 penyakit diare menempati urutan ke 4 dengan jumlah 598 kasus, 128 diantaranya adalah lansia, pada tahun 2015 menempati urutan ke 3 dengan jumlah 706 kasus, 159 diantaranya adalah lansia. Puskesmas Ngadiluwih memiliki wilayah kerja sebanyak 7 desa, yaitu Desa Ngadiluwih, Purwokerto, Badal, Banggle, Branggahan, Seketi, dan Tales. Pada bulan januari 2016 sampai bulan september 2016 jumlah kasus diare pada lansia tertinggi berada di Desa Tales yaitu sebesar 25 kasus diare pada lansia dari 62 kasus diare pada semua umur.

Berdasarkan studi pendahuluan yang dilakukan peneliti pada tanggal 8 Oktober 2016 di posyandu lansia di Desa Tales Wilayah Kerja Puskesmas Ngadiluwih dengan cara wawancara kepada 10 orang lansia, diketahui bahwa 6 orang lansia belum mengetahui tentang pertolongan pertama pada diare dan tidak melakukan pertolongan pertama secara tepat serta sering membiarkan penyakitnya sembuh dengan sendirinya. Mereka mengatakan hanya meminum jamu untuk mengobatinya, sehingga lansia yang dibawa ke puskesmas sudah mengalami dehidrasi. Sedangkan ke empat lansia yang lain mengatakan jika mengalami diare mereka meminum banyak air putih.

Masalah kesehatan pada lansia
secara umum disebabkan karena menurunnya fungsi organ tubuh, sehingga aktivitas dan metabolisme tubuh otomatis menurun. Sebagai suatu proses alamiah fenomena di atas juga diikuti dengan menurunnya energi dan kapasitas 
pencernaan yang umum dimulai usia 50 tahun (Padila, 2013).

Salah satu solusi yang dapat dilakukan untuk pencegahan terjadinya dehidrasi pada diare adalah dengan memberikan pertolongan pertama yang tepat bagi penderita. Diperlukan pengetahuan bagi penderita untuk mengetahui pertolongan apa saja yang dapat dilakukan apabila gejala diare sudah muncul. Pemberian health education merupakan metode yang tepat untuk menambah pengetahuan lansia.

Peneliti tertarik untuk melakukan penelitian tetang "komunikasi health education terhadap pengetahuan lansia tentang pertolongan pertama pada diare di Wilayah Kerja Puskesmas Ngadiluwih Kabupaten Kediri”.

Tujuan penelitian ini Untuk Mengetahui Pengaruh komunikasi health education terhadap pengetahuan lansia tentang pertolongan pertama pada diare di Wilayah Kerja Puskesmas Ngadiluwih Kabupaten Kediri.

\section{TINJAUAN PUSTAKA}

\section{Komunikasi Health Education}

$\begin{array}{crr}\text { Lulu } & \text { Yunita } & \text { (2016) pada } \\ \text { penelitiannya } & \text { tentang } & \text { efektivitas }\end{array}$ pendidikan kesehatan dengan metode ceramah terhadap tingkat pengetahuan ibu dalam penanganan diare balita menjelaskan bahwa adanya perbedaan pengetahuan tentang penanganan diare sebelum dan sesudah diberikan pendidikan kesehatan dengan metode ceramah.

Menurut Machfoed (2005), pendidikan kesehatan merupakan sejumlah pengalaman yang berpengaruh secara menguntungkan terhadap kebiasaan, sikap, dan pengetahuan yang ada hubungannya dengan kesehatan perseorangan, masyarakat, dan bangsa. Hasil yang diharapkan dari suatu promosi atau pendidikan kesehatan adalah perilaku kesehatan, atau perilaku untuk memelihara dan meningkatkan kesehatan yang kondusif oleh sasaran dari promosi kesehatan. (Notoadmojo, 2012)

$$
\text { Health education tentang }
$$

pertolongan pertama pada diare sangat penting untuk meningkatkan pengetahuan lansia karena mereka lebih mudah terkena infeksi akibat dari penurunan sistem kekebalan tubuh. Jika yang terjadi adalah penurunan kekebalan tubuh, diare yang menyerang lansia sangat dimungkinkan disebabkan oleh adanya infeksi bakteri (Soegijanto, 2006).

Definisi lain dari komunikasi kesehatan menurut Health Communication Partnership's M/MC Health Communication Materials Database ialah Seni dan teknik penyebarluasan informasi kesehatan yang bermaksud mempengaruhi dan memotivasi individu, mendorong lahirnya lembaga atau institusi baik sebagai peraturan ataupun sebagai organisasi di kalangan audiens yang mengatur perhatian terhadap kesehatan. Komunikasi kesehatan meliputi informasi tentang pencegahan penyakit, promosi kesehatan, kebijaksanaan pemeliharaan kesehatan, regulasi bisnis dalam bidang kesehatan, yang sejauh mungkin mengubah dan membaharui kualitas individu dalam suatu komunikasi atau masyarakat dengan mempertimbangkan aspek ilmu pengetahuan dan etika (Liliweri, 2007: 47).

\section{Lansia dan Pengetahuan Pertolongan Pertama Diare}


Masalah yang terjadi pada lansia seperti masalah kesehatan fisik dan kesehatan psikologis harus mendapat perhatian yang khusus. Atun (2010) menyebutkan bahwa penurunan kesehatan fisik ini dapat memicu terjadinya penyakit. Selain masalah tersebut, menurut Menurut Setiati dkk (2014) adanya perubahan kognitif yang terjadi pada lansia meliputi berkurangnya kemampuan meningkatkan fungsi intelektual dan proses informasi melambat.

Meningkatkan pengetahuan dapat mempengaruhi seseorang termasuk juga perilaku seseorang akan pola hidup terutama dalam memotivasi untuk sikap berperan serta dalam meningkatkan status kesehatan (Wawan dan Dewi, 2010). Menurut Rogers yang dikutip oleh Wawan dan Dewi (2010) perilaku yang didasarkan oleh pengetahuan akan lebih langgeng daripada perilaku yang tidak didasari oleh pengetahuan.

Palancoi (2014) menyatakan pada penelitiannya bahwa, salah satu faktor yang mempengaruhi kejadian diare adalah pengetahuan, perilaku, dan lingkungan.

$$
\text { Nungky Kustantya }
$$

menjelaskan pada penelitian hubungan tingkat pengetahuan dengan perilaku hidup bersih dan sehat (PHBS) pada lansia mengungkapkan semakin kurang tingkat pengetahuan lansia tentang perilaku hidup bersih dan sehat maka semakin tinggi terkena infeksi penyakit. Prasetyoningsih (2015) juga menjelaskan pada penelitiannya tentang hubungan antara pengetahuan tentang cuci tangan yang benar dengan kejadian diare pada lansia bahwa terdapat hubungan yang signifikan antara pengetahuan tentang mencuci tangan yang benar dengan kejadian diare pada lansia.

\section{METODE PENELITIAN}

Desain penelitian yang digunakan dalam penelitian ini berdasar Notoadmojo (2010) adalah pre-experimental dengan rancangan one-group pra-post test. Populasinya merupakan semua lansia usia $\geq 60$ tahun yang aktif dalam posyandu lansia dan tinggal di Desa Tales Wilayah Kerja Puskesmas Ngadiluwih Kabupaten Kediri dengan sampel 98 responden secara simple random sampling. Instrumen yang digunakan adalah kuesioner pengetahuan pra-post test tentang pertolongan pertama pada diare kemudian dianalisis dengan Uji Wilcoxon.

\section{HASIL PENELITIAN DAN PEMBAHASAN}

\section{Hasil Penelitian}

\section{Karakteristik Responden}

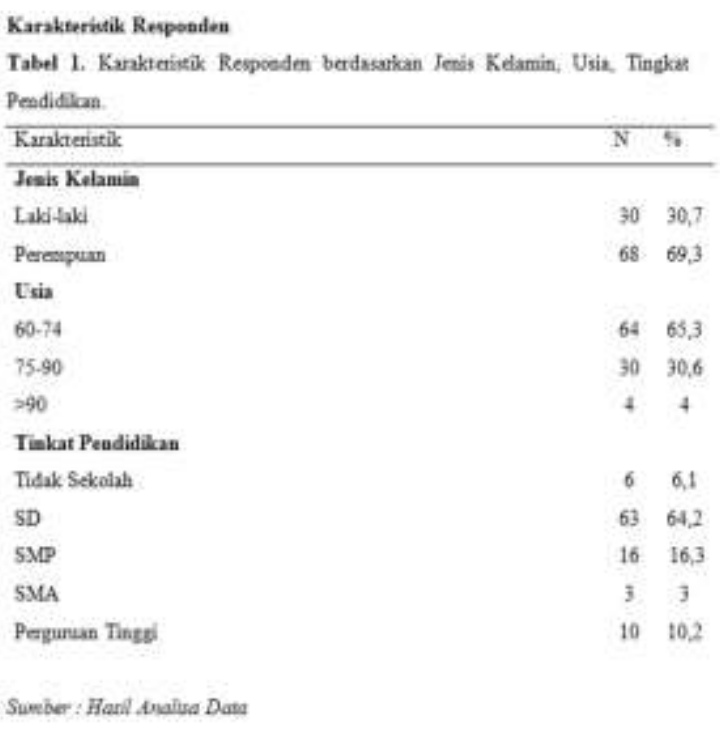




\begin{tabular}{|c|c|c|}
\hline Karktenisk & $x$ & 5 \\
\hline \multicolumn{3}{|l|}{ Jeais Kelanin } \\
\hline Labilidi & 30 & 30,7 \\
\hline Perenguan & 68 & 693 \\
\hline \multicolumn{3}{|l|}{ Tsin } \\
\hline 62.74 & 64 & 653 \\
\hline 75.90 & in & 30,6 \\
\hline$>90$ & 4 & 4 \\
\hline \multicolumn{3}{|l|}{$\underline{\text { Timbat Peadichan }}$} \\
\hline Tidars Sckolath & 6 & 6,1 \\
\hline SD & 63 & 642 \\
\hline $\mathrm{SVP}$ & 16 & 163 \\
\hline SMA & 3 & 3 \\
\hline Pegrnun Tinge & 10 & 10,2 \\
\hline
\end{tabular}

\section{Karakteristik Variabel}

Tabel 2. Karakteristik pengetahuan lansia tentang pertolongan pertama pada diare di Wilayah kerja Pukesmas Ngadiluwih Kabupaten Kediri sebelum health education

\begin{tabular}{|c|c|}
\hline Bastentis & J 16 \\
\hline \multicolumn{2}{|l|}{ Pengthinan } \\
\hline Brergy & 82846 \\
\hline Oint & 1I 11. \\
\hline Bat. & + 4 \\
\hline
\end{tabular}

Tabel 3. Kankterisilk pengethan lansia teatung petolongan petama pada dare

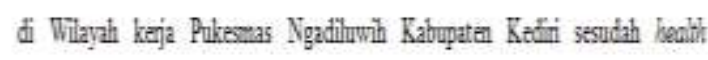

exication

\begin{tabular}{lcc}
\hline Karahteistle & N & $\%$ \\
\hline Pengetahuan & & \\
Kurng & 0 & 0 \\
Cukng & 13 & 132 \\
Bilk & 85 & 867
\end{tabular}

\section{Sumber: Hasi thritra Datra}

\section{Hasil Uji Statistik}

Tabel 4. Hasil uji statistik health education terhadap pengetahuan lansia tentang pertolongan pertama pada diare di Wilayah Kerja Puskesmas Ngadiluwih Kabupaten Kediri tanggal 13 Mei 2017-14 Juni 2017 dengan uji Wilcoxon dapat dilihat pada tabel dibawah ini :

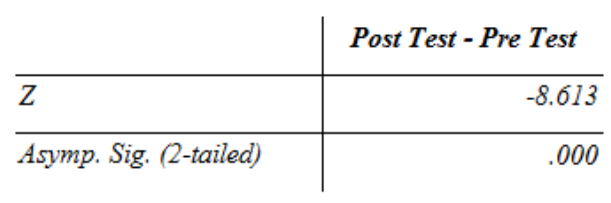

Hasil uji statistik diatas yang menggunakan uji statistik Wilcoxon dengan $\alpha=0,05$, didapatkan nilai $p$ value $=0,000$ sehingga $0,000<0,05$. Dapat disimpulkan bahwa $\mathrm{H} 0$ ditolak yang berarti ada pengaruh health education terhadap pengetahuan lansia tentang pertolongan pertama pada diare di Wilayah Kerja Puskesmas Ngadiluwih Kabupaten Kediri.

\section{Pembahasan}

Pengetahuan Lansia tentang pertolongan pertama pada diare di Wilayah Kerja Puskesmas Ngadiluwih Kabupaten Kediri sebelum Komunikasi health education 
Hasil penelitian health education terhadap pengetahuan lansia tentang pertolongan pertama pada diare di Wilayah Kerja Puskesmas Ngadiluwih Kabupaten Kediri sebelum dilakukan health education kepada 98 responden, sebanyak $83(84,6 \%)$ responden berpengetahuan kurang.

$$
\text { Usia merupakan faktor internal }
$$

yang mempengaruhi pengetahuan seseorang, semakin bertambah usia maka semakin menurun fungsi kognitif seseorang. Namun, apabila seseorang tetap menjaga fungsi kognitif dan berperilaku sesuai dengan pengetahuan, kesadaran, dan sikap yang dapat menjaga kesehatan tubuhnya, maka usia bukan menjadi satusatunya alasan seseorang untuk tetap sehat. Penelitian yang dilakukan oleh Palancoi (2014) menegaskan bahwa usia bukan satu-satunya faktor yang mempengaruhi pengetahuan seseorang.

Tingkat pendidikan juga merupakan faktor internal yang mempengaruhi tingkat pengetahuan seseorang. Namun pada penelitian ini, tingkat pendidikan lansia tidak menjadi patokan akan pengetahuan yang dipunya mengingat pendidikan merupakan keadaan lansia yang terdahulu.

\section{Pengetahuan Lansia tentang pertolongan pertama pada diare sesudah komunikasi health education}

Hasil penelitian health education terhadap pengetahuan lansia tentang pertolongan pertama pada diare di Wilayah Kerja Puskesmas Ngadiluwih Kabupaten Kediri sesudah dilakukan komunikasi health education kepada 98 responden, sebanyak $85 \quad(86,7 \%)$ responden berpengetahuan baik.

Pada kuesioner dengan nomor item 1, 2, dan 3, semua responden dapat menjawab pernyataan dengan benar tentang pemahaman penyakit diare, sedangkan pada nomor item 5 sampai dengan $14 \quad 84,6 \%$ responden dapat menyebutkan tentang pertolongan pertama pada diare. Sarwono (2008) menegaskan bahwa semakin banyak informasi yang didapat maka semakin bertambah pula pengetahuan seseorang.

Lansia yang hidup sendiri atau lansia yang sering ditinggal dirumah sendiri oleh keluarganya karena bekerja harus dibekali oleh pengetahuan maupun pertolongan pertama untuk kesehatannya. Banyaknya makanan dan minuman yang dijual bebas atau yang dimasak sendiri dengan keadaan kurang matang dan higienis dapat menyebabkan diare pada lansia. Makanan yang terlalu pedas dan asam juga dapat merangsang terjadinya diare. Selama pertolongan pertama dapat dilakukan sendiri oleh lansia maka komplikasi seperti dehidrasi tidak akan terjadi ataupun dapat diminimalisir.

Responden sesudah mendapatkan informasi melalui pendidikan kesehatan terjadi peningkatan pengetahuan tentang pertolongan pertama pada diare. Hal ini disebabkan karena sebelum mendapatkan pendidikan kesehatan tentang pertolongan pertama pada diare, lansia cenderung memilih obat alternatif seperti jamu dan mengandalkan pengalaman saja tanpa tahu efek samping maupun komplikasi yang dapat diakibatkan oleh diare.

Nursalam (2011) menyatakan peningkatan pengetahuan tidak mutlak diperoleh dari pendidikan formal saja, akan tetapi dapat diperoleh dari pendidikan non formal. Pendidikan kesehatan dilakukan untuk memberi pengetahuan melalui informasi yang pasti dan terdapat referensi yang akurat. 
JURNAL NOMOSLECA

Volume 3, Nomor 2, Oktober 2017

Komunikasi health education terhadap pengetahuan lansia tentang pertolongan pertama pada diare di Wilayah Kerja Puskesmas Ngadiluwih Kabupaten Kediri

Sebelum health education 83 responden atau $84,6 \%$ responden berpengetahuan kurang, sedangkan sesudah health education 85 responden atau $86,7 \%$ responden berpengetahuan baik. Hasil uji statistik pada tabel 4.9 menunjukkan bahwa $p$ value $<\alpha$ atau $0,000<0,05$, sehingga dapat disimpulkan bahwa terdapat perubahan antara pengetahuan sebelum dan sesudah health education tentang pertolongan pertama pada diare.

Pendidikan kesehatan tentang pertolongan pertama pada diare dilakukan untuk menekan angka komplikasi yang dapat diakibatkan oleh diare. Harnowo (2012) menegaskan bahwa diare dapat berakibat fatal bagi penderita.

Pemberian komunikasi health education akan memberikan pengaruh pada pengetahuan seseorang yang ingin mendengarkan dan turut serta dalam penyuluhan, bukan mustahil pengetahuan akan lebih baik bila dibandingkan dengan yang tidak mengikuti (Notoatmodjo, 2011).

Hasil penelitian ini menunjukkan terjadinya peningkatan pengetahuan kepada 98 responden. Hal tersebut disebakan karena lansia mendengar informasi tentang pertolongan pertama pada diare dan dapat memahami penjelasan yang disampaikan oleh peneliti.

Berdasarkan uraian diatas dapat dikatakan bahwa lansia masih bisa merubah pengetahuan dan meningkatan pengetahuannya dengan cara mendapat pengetahuan dan informasi positif tentang pertolongan pertama pada diare yang berguna untuk dirinya sendiri dan orang disekitarnya.

\section{PENUTUP}

\section{Simpulan}

1. Sebagian besar responden sebelum diberikan komunikasi health education tentang pertolongan pertama pada diare memiliki pengetahuan dengan kategori kurang yaitu sebanyak 83 responden $(84,6 \%)$ dari total 98 responden.

2. Sesudah diberikan komunikasi health education tentang pertolongan pertama pada diare responden memiliki pengetahuan dengan kategori baik yaitu sebanyak 85 responden $(86,7 \%)$ dan pengetahuan dengan kategori cukup sebanyak 13 responden $(13,2 \%)$.

3. Ada pengaruh komunikasi health education terhadap pengetahuan lansia tentang pertolongan pertama pada diare di Wilayah Kerja Puskesmas Ngadiluwih Kabupaten Kediri.

\section{Saran}

1. Bagi responden

Diharapkan lebih memperbanyak informasi dan dapat menerapkan pertolongan pertama pada diare agar pertolongan pertama dapat segera dilakukan sedini mungkin karena tak jarang lansia hidup sendiri atau di tinggal keluarganya bekerja dalam waktu yang lama.

2. Bagi lahan penelitian di Puskesmas Ngadiluwih Kabupaten Kediri

Diharapkan Puskesmas membuat SOP tentang pertolongan pertama pada diare untuk disebarluaskan tidak hanya untuk pasien yang berada di puskesmas namun kepada masyarakat luas agar 
dapat mencegah komplikasi seperti dehidrasi.

3. Bagi Petugas Kesehatan

Diharapkan petugas yang terjun langsung dilapangan mau dan mampu memberikan pendidikan kesehatan bagi para lansia di posyandu maupun door to door bagi lansia yang memiliki keterbatasan fisik agar tetap mendapat perhatian.

4. Bagi Peneliti Selanjutnya

Diharapkan peneliti selanjutnya dapat mengembangkan penelitian ini dengan mengikutsertakan keluarga lansia untuk pertolongan pertama pada diare, misalkan dengan judul "peran keluarga dalam penerapan pertolongan pertama pada diare".

\section{DAFTAR PUSTAKA}

Depkes RI. 2013. Riset Kesehatan Dasar. Jakarta: Badan Penelitian danpengembangan Kesehatan Kementrian Kesehatan RI.

Atun. 2010. Lansia sehat \& bugar. Jakarta: Penerbit kreasi wacana.

Harnowo, Putro Agus (ed). 2013. Pertolongan Pertama dan Penanganan Darurat. DetikHealth.

Kusantya, N., Anwar, M. S. 2013. Hubungan Tingkat Pengetahuan Dengan Perilaku Hidup Bersih Dan Sehat (PHBS) Pada Lansia. Malang: Rumah Sakit Saiful Anwar.

Liliweri, Alo. (2007). Dasar-dasar Komunikasi Antarbudaya. Yogyakarta: Pelajar Pustaka.

Machfoedz. I, Suryani. E, Sutrisno., Santoso. S. 2005. Pendidikan
Kesehatan Bagiandari Promosi

Kesehatan. Yogyakarta: Fitramaya

Notoadmojo, S. 2010. Metodologi penelitian kesehatan. Jakarta: Rineka Cipta.

Notoadmojo, S. 2012. Promosi Kesehatan dan perilaku kesehatan. Jakarta: Rineka Cipta.

Nursalam. (2011). Konsep dan penerapan metodologi penelitian ilmu keperawatan. Jakarta : Salemba Medika

Padila. 2013. Asuhan Keperawatan Penyakit Dalam. Yogyakarta: Nuha Medika

Palancoi, Najamudin Andi. 2014. Hubungan antara pengetahuan dan lingkungan dengan kejadian diare akut di Kelurahan Pabbundukang Kecamatan Pangkajene Kabupaten Pangkep. Makassar: UIN Alauddin Makassar.

Prasetyoningsih. 2015. Hubungan antara pengetahuan tentang cuci tangan yang benar dengan kejadian diare pada lansia di Puskesmas Nguntoronadi I Wonogiri. Surakarta: STIKes Kusuma Husada Surakarta.

Sarwono. 2008. Ilmu Kandungan. Jakarta : Yayasan Bina Pustaka.

Setiati S, Alwi I, Sudoyo AW, Stiyohadi B, Syam AF. 2014. Buku ajar ilmupenyakit dalam jilid I. VI. Jakarta: InternaPublishing.

Soegijanto, S. 2006. Demam Berdarah Dengue. Edisi 2. Surabaya : Airlangga University Press. 
JURNAL NOMOSLECA

Volume 3, Nomor 2, Oktober 2017

Tjay, Tan. H \& Rahardja, Kirana. 2007.

Obat-obat penting : Khasiat,

Penggunaan dan Efek Sampingnya.

Edisi Keenam. Jakarta : Elex Media

Computindo.

Wawan, A., Dewi, M. 2010. Teori dan pengukuran pengetahuan, sikap dan perilaku manusia. Yogyakarta: Nuha Medika.

Yunita, Lulu. 2016. Efektivitas pendidikan kesehatan dengan metode ceramah terhadap tingkat pengetahuan ibu dalam penanganan diare balita di sekitar UPT TPA Cipayung Depok. Jakarta: UIN Syarif Hidayatullah Jakarta. 